\title{
BUSINESS CYCLE IMPACT ON POLLUTION LEVELS IN THE CITY OF MADRID USING FUNCTIONAL DATA
}

\author{
Betancourt ALEJANDRO $^{1}$ (D), Ramos JAVIER ${ }^{2}$, Wirth ESZTER ${ }^{2}$ (D)
}

DOI: 10.21163/GT_2020.152.02

\begin{abstract}
:
The aim of this paper is to analyse whether the evolution of $\mathrm{NO}_{2}$ and $\mathrm{PM}_{10}$ emission levels in the Madrid metropolitan area with heavy traffic are affected by business cycles (comprised of a boom, recession and recovery). Therefore, we explore if economic developments act as automatic environmental stabilizers in an urban context in order to provide guidelines for environmental policymaking in large cities. Considering the continuous nature of the particles that this paper analyses, functional data have been used and the most suitable statistical method has been applied to this information's typology. The aim is to capture the behaviour of NO2 and PM10 particles throughout the booming years (2001-2005), the recession (2008-2012) and the recovery (2014-2018) periods. The results obtained through the Kendall's functional Tau statistic have revealed that the similarities and differences found between the booming years, the recession and the recovery prove the effect of the economy's cyclical fluctuations on pollution levels. This is due to the fact that the negative and close to zero correlations obtained through these periods represent a sign that pollution levels regarding these two particles are significantly different during the phases of business cycles.
\end{abstract}

Key-words: Pollution, Urban Environmental Policy, Business Cycle, Functional Data, Kendall Correlation.

\section{INTRODUCTION}

$\mathrm{NO}_{2}$ and $\mathrm{PM}_{10}$ particles represent two of the pollutants that have concerned international scientific communities the most (Medina, Zanobetti \& Schwartz, 2006; Lelieveld et al, 2002; EEA, 2018) due to their negative effects on global warming and human health (World Health Organization, 2014). When it comes to $\mathrm{NO}_{2}$, scientists have highlighted its role in generating other harmful particles such as $\mathrm{O}_{3}$ and $\mathrm{PM}_{5}$ (Hysenaj, 2019, Archer, Brodie \& Rauscher, 2019). This substance, which can be found in urban air, mainly comes from NO rusting, whose main sources are emissions by automobile combustion engines, especially those that run on diesel.

During year 2018 in Madrid, the city that is the focus of this research, 7 out of the 24 air monitoring stations that measure $\mathrm{NO}_{2}$ levels surpassed the annual threshold value recommended by the World Health Organization (WHO) (Ceballos et al, 2018; ACDGMAS, 2018). This particle's highest value $\left(55 \mu \mathrm{g} / \mathrm{m}^{3}\right)$ was detected within the area covered by the Escuela Aguirre air monitoring station (Central Madrid). When it comes to $\mathrm{PM}_{10}, 4$ out of the 13 air monitoring stations recorded figures that also exceeded the annual threshold value recommended by the WHO (Ceballos M.A, et al., 2018; Spain Government, Ministry for Ecological Transition, 2018).

Economic activities play an outstanding role in this economic context with high production and consumption levels seriously damaging environmental health. An empirical study that was carried out throughout this document brought to light that high pollution rates of certain particles, such as $\mathrm{NO}_{2}$ and $\mathrm{PM}_{10}$, vary according to the economy's business cycle (see Figures 2 and 3).

\footnotetext{
${ }^{1}$ Universidad Pontificia Comillas, Departament of Quatitative Methods mabetancourt@ comillas.edu

${ }^{2}$ Universidad Pontificia Comillas, Economic Departament,ajramos@icade.comillas.edu,ewirth@comillas.edu
} 
These particles' pollution levels are higher during the economic booms than during crises and recoveries. Pollution levels are increasing anew during the current recovery period, although at a slower pace than throughout the previous intensive economic boom.

If this fact was true from a statistical point of view, the following hypothesis could be contemplated: Do business cycles act as automatic regulators for certain particles' pollution levels? With a view to answering this formulation, this study aims at showing if the evolution of $\mathrm{NO}_{2}$ and $\mathrm{PM}_{10}$ pollution levels in Central Madrid's heavy traffic zones is affected by business cycles (comprised of a boom, recession and recovery).

Research studies including mathematical and statistical techniques have a crucial role in shedding light on the behaviour and trends of polluting substances in such circumstances. The search for patterns through mathematical models considering the specific features of the orography and meteorological conditions in the places that are the focus of our study have been deeply analysed by many authors (Salvador et al, 2015).

However, almost all the articles published so far consider $\mathrm{NO}_{2}$ and $\mathrm{PM}_{10}$ pollution levels as a discrete variable over time, and consequently apply traditional statistical techniques. This problem entails the lack of those scientific methods that could enable a more thorough research on these particles' behaviour. This is the reason why this article takes into account the continuous nature of the particles, and therefore the data are considered as functions. This particularity requires the application of statistics on functional data, such as the KFT, developed by Valencia, Lillo \& Romo, (2019).

\section{STUDY AREA AND DATA}

Daily studies on $\mathrm{NO}_{2}$ and $\mathrm{PM}_{10}$ particles were carried out during the time frames 2001-2005, 2008-2012 and 2014-2018, which correspond to the stages of boom, recession and recovery of the last 20-year business cycle, respectively (see Fig. 1a and 1b). To do so, 5 air quality-monitoring stations were selected (Escuela Aguirre, Cuatro Caminos, Plaza de España, and Barrio del Pilar), all located in the urban core of Madrid City. These stations were selected because they correspond to those areas that are affected by the heaviest traffic levels in the capital. Any interested reader can access the most up-to-date data on the web page of Madrid City Council, which is regularly collected and made available by the Comprehensive Air Quality System. Data was processed with MATLAB V18b software system.

Figs. 1a and 1b depict the average annual $\mathrm{NO}_{2}$ and $\mathrm{PM}_{10}$ pollution levels between years 2001 and 2017 for the 5 air monitoring stations that are considered in this study. On both charts it can be observed that during the Spanish economy's boom (2001-2005) the levels remained stable and substantially exceeded the WHO's regulation. However, through the economic crisis (2008-2012) both pollutants suffered a downward trend until registering a slight increase since year 2014, which corresponds to the recovery stage. Each phase of the Spanish economy's business cycle can be observed in Figs. 2a and 2b.

Fig.2a displays nominal GDP annual growth rates in Madrid City, the Community of Madrid and Spain from 2000 until 2017, while Fig. 2b represents national real GDP growth rates during the same time frame. We can observe the three stages of the last Spanish business cycle on both charts: an intense economic growth prior to the 2008 crisis; a substantial fall in production (and employment) throughout the 2008-2013 global economic crisis; and followed by an economic recovery since 2014, blurred by an uncertain outlook nowadays.

The existence of three clearly defined periods, each comprised of 5 years, justify the choice of polluting particle emission samples for each one of them. By analysing each period, we will be able to study the impact of each stage of the business cycle (economic growth, economic crisis and recovery) on pollution levels and thus, determine if business cycles can be considered as automatic regulators of pollution levels. 


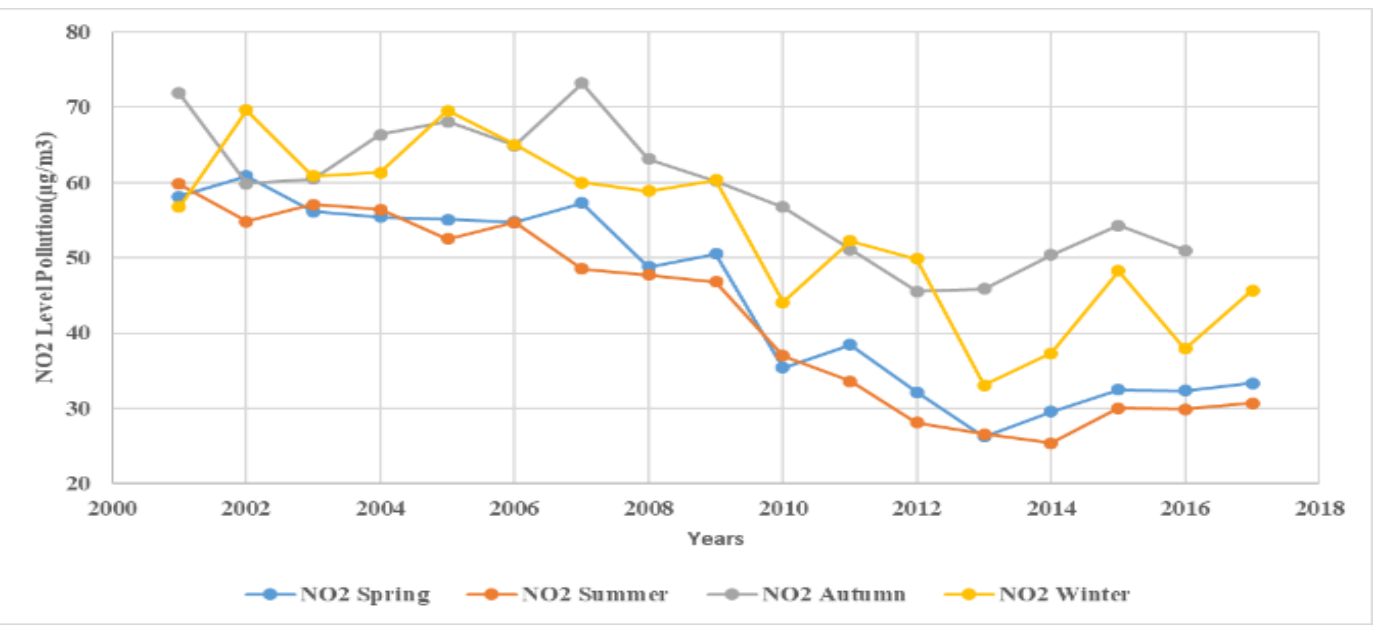

Fig. 1a. Annual average, $\mathrm{NO}_{2}$ in Madrid (2001-2017).

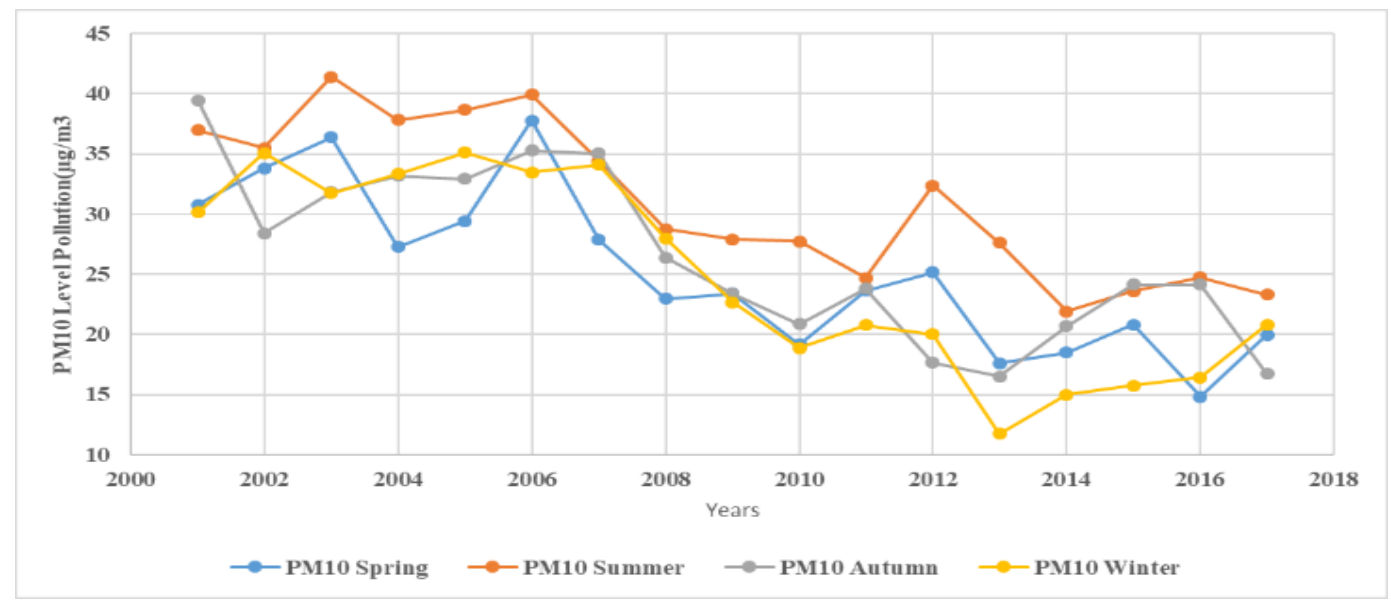

Fig. 1b. Annual average, $\mathrm{PM}_{10}$ in Madrid (2001-2017).

(Source: authors' calculations based on data)

\section{METHODOLOGY}

\subsection{Functional Kendall's Tau Correlation}

Even though the evolution of many variables of interest takes place over a continuous time period, in the context of scientific investigations their study is often carried out from a more transversal and discrete perspective, which leads to a loss of relevant information regarding the 'natural' behavior of the phenomenon under study (Kovács, 2018; Fontana, Tavoni \& Vantini, 2019). Therefore, the choice to resort to functions as a mathematical tool seems to be natural for a scientist who aims at capturing the continuous-time behaviour of a phenomenon ( $\mathrm{Li} \& \mathrm{Chow}, 2005)$. Once we allow ourselves to interpret the observations of a process as function realizations, the tools adopted for the statistical analysis must be consistent with the available data type. 


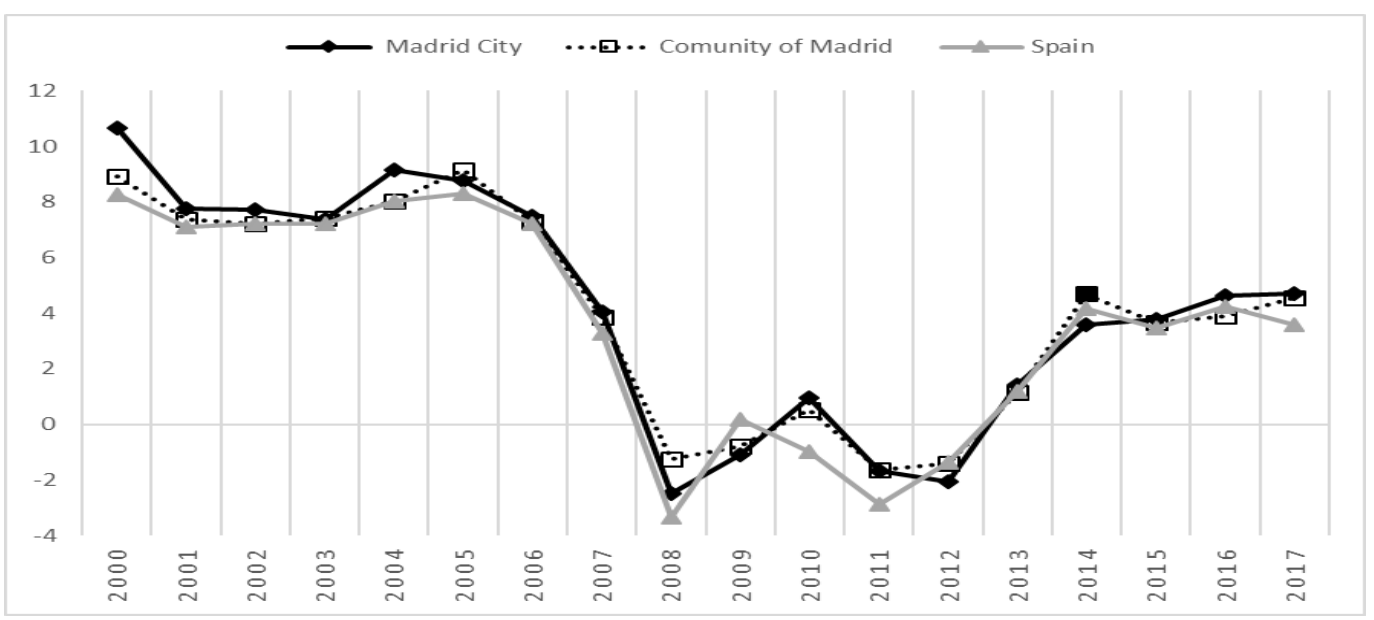

Fig 2a. Nominal GDP annual growth rates (\%).

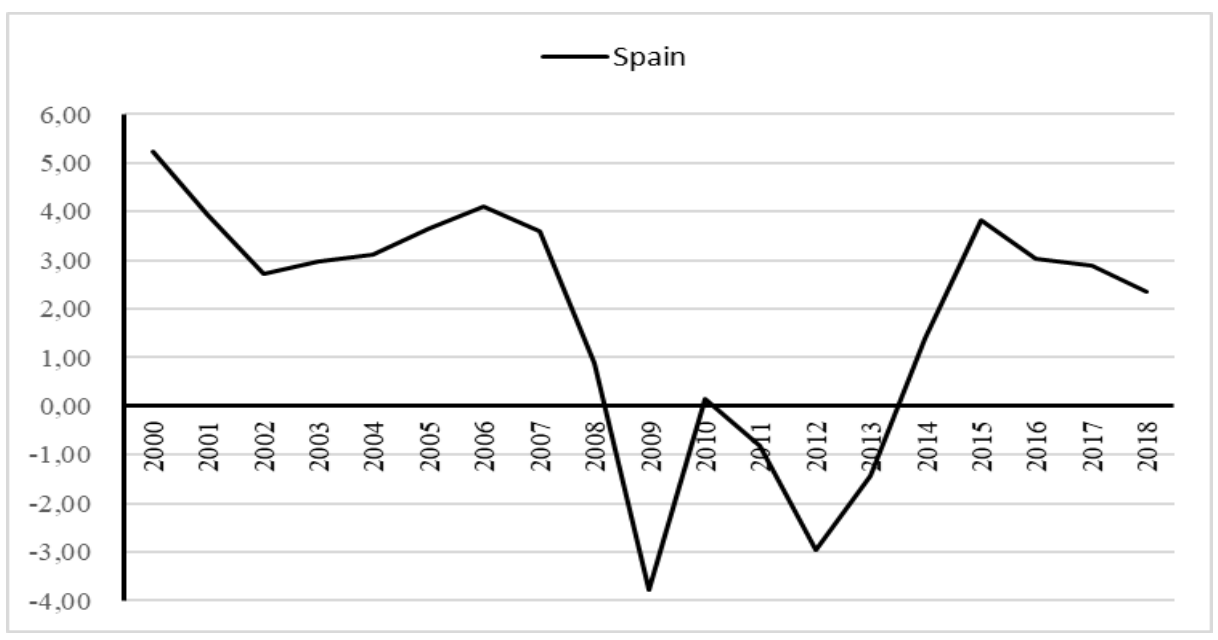

Fig 2b. Real GDP annual growth rates, Spain (\%).

(Source: authors' calculations based on data from the Spanish Statistical Institute)

For example, this is the case for the techniques adopted by regression analysis (Escabias, Aguilera \&Valderrama, 2004), by the measures of depth (López-Pintado \& Romo, 2009) and by the dependency and correlation analysis (Leurgans, Moyeed \& Silverman, 1993; Li \& Chow, 2005; Valencia, Lillo \& Romo, 2019). Specifically, in recent years in each of these contexts classical statistics techniques have been extended to the scope of functional analysis.

For the kind of investigation that we aim to do in our work, which requires us to study the relationships between the pollution behaviors of $\mathrm{NO}_{2}$ and $\mathrm{PM}_{10}$ particles and the air quality in different geographical districts of the MMA, we chose to implement the Functional Kendall's Tao (FKT), proposed by Valencia, Lillo \& Romo (2019). The FKT is the extension to a functional context of the classic Kendall's Tao coefficient (Kendall, 1955), which relies on the distinction between concordant and discordant observations between two sets of data. In particular, the FKT is inspired by the idea that the sets to be analyzed are discrete realizations along curves. 
Functional Kendall's Tau (FKT): If $\left(X_{1}, Y_{1}\right)\left(X_{2}, Y_{2}\right)$ are copies of a stochastic bivariate process $\{(X(t), Y(t): t \in I\}$, where $I=[a, b]$. The population version of the Functional Kendall's Tao (FKT) would be:

$$
\tau=\left[P\left\{X_{1} \prec X_{2}, Y_{1} \prec Y_{2}\right\}+P\left\{X_{2} \prec X_{1}, Y_{2} \prec Y_{1}\right\}\right]-1
$$

In particular, if we consider a sample $\left(x_{1}, y_{1}\right) \ldots\left(x_{n}, y_{n}\right)$ of a bivariate random process $(X, Y)=$ $\{(X(t), Y(t): t \in I\}$ within the compact interval $I=[a, b]$, then the empirical version of the Functional Kendall Tau would be given by

$$
\tau=\left(\begin{array}{l}
n \\
2
\end{array}\right)^{-1} \sum_{i<j}^{n}\left[2 I\left(x_{1} \prec x_{2}, y_{1} \prec y_{2}\right)+2 I\left(x_{2} \prec x_{1}, y_{2} \prec y_{1}\right)\right]-1
$$

The realizations of the stochastic process are taken as functions. When the FKT takes 1 as a value then the sets of functions are perfectly positively correlated. Instead, if $\hat{\tau}$ is equal to -1 when their correlation is perfectly negative and if equal to 0 when they display absence of correlation. When the FKT takes increasing values between 0 and $1(-1)$, this indicates increasing positive (negative) degrees of correlation between the pair of sets.

Finally, the KTF is robust, which means it displays low sensitivity to the presence of data outliers. Robustness is an important property for these kinds of coefficients, since any point value that is erroneously captured will not significantly affect the overall analysis and conclusions. These and other properties of the functional coefficient are discussed by Valencia, Lillo \& Romo- (2019).

\section{RESULTS AND DISCUSSIONS}

The use of functions as baseline information that describe daily pollution levels in each air monitoring station, justified by the information's nature, allows us to take into account the evolution of $\mathrm{NO}_{2}$ an $\mathrm{PM}_{10}$ in a continuous way over time. On the contrary, the conventional statistics (average, standard deviation), often used and applied on discrete data, are sensitive to extreme values. In many cases their calculation makes it impossible to describe everything that occurs concerning pollution in the medium-long run. In contrast, some of the statistics defined as functions allow to capture their whole evolution over the study period as it has been proved by Valencia, Lillo \& Romo (2019).

For the functional correlation analysis each air monitoring station's data correspond to three sets of 5 curves each, which describe the daily pollution levels over the periods 2001-2005, 2008-2012 and 2014-2018. These periods have been selected in order to match them with the three stages of the Spanish and Madrilenian business cycle. Each function contains approximately 365 discretisation points that correspond to the total days of a year. The Kendall Tau coefficient between business cycles is calculated through functional data. This way correlation coefficients between each stage of the business cycle are thoroughly studied in order to analyse pollution behaviours under each stage's effects. The results were obtained by programming the proposed functional statistic on MATLAB18b.

Each pair of the business cycle's stages for the same air monitoring station displaying a low correlation or a negative correlation explains that pollution behaviours are very different between them, and thus, are a sign that business cycles act as automatic regulators on certain particles' pollution levels. Tables 1-7 show for each study period the Kendall Tau's most relevant results for air monitoring stations located in those areas of Madrid City that suffer from heavy traffic.

Table 1 and 2 depict the correlations between periods 2001-2005 and 2008-2012 for $\mathrm{NO}_{2}$ and $\mathrm{PM}_{10}$ substances in the Cuatro Caminos air monitoring station. In case of the former pollutant, the correlation between the two periods is -0.2 , which indicates a weak linkage between pollution levels during the economic boom and the recession. As for the second pollutant, the correlation is moderately negative (-0.8), which means that during most of the booming years (2001-2005) pollution trends are the opposite to the trends during the recession period (2008-2012), as it can be observed in Table 2. 
Similar results are shown in the Escuela Aguirre, Plaza de España and Barrio del Pilar air monitoring stations, whose results are reflected in tables 3 to 6 , respectively.

Kendall Functional Correlation for $\mathrm{NO}_{2}$.

Table 1.

\begin{tabular}{|c|ccc|}
\hline Station (Years) & $\begin{array}{c}\text { Cuatro Caminos } \\
(14-18)\end{array}$ & $\begin{array}{c}\text { Cuatro Caminos } \\
(08-12)\end{array}$ & $\begin{array}{c}\text { Cuatro Caminos } \\
(01-05)\end{array}$ \\
\hline Cuatro Caminos (01-05) & 0,8 & $-0,2$ & 1 \\
Cuatro Caminos (08-12) & $-0,4$ & 1 & $-0,2$ \\
Cuatro Caminos (14-18) & 1 & $-0,4$ & 0,8 \\
\hline
\end{tabular}

Kendall Functional Correlation for $\mathbf{P M}_{10}$.

Table 2.

\begin{tabular}{|c|ccc|}
\hline Station (Years) & $\begin{array}{c}\text { Cuatro Caminos } \\
(14-18)\end{array}$ & $\begin{array}{c}\text { Cuatro Camino s } \\
(08-12)\end{array}$ & $\begin{array}{c}\text { Cuatro Caminos } \\
(01-05)\end{array}$ \\
\hline Cuatro Caminos (01-05) & 0,4 & $-0,8$ & 1 \\
Cuatro Caminos (08-12) & $-0,2$ & 1 & $-0,8$ \\
Cuatro Caminos (14-18) & 1 & $-0,2$ & 0,4 \\
\hline
\end{tabular}

Kendall Functional Correlation for $\mathrm{NO}_{2}$.

Table 3 .

\begin{tabular}{|l|ccc|}
\hline Station (Years) & $\begin{array}{c}\text { Escuelas Aguirre } \\
(14-18)\end{array}$ & $\begin{array}{c}\text { Escuelas Aguirre } \\
(08-12)\end{array}$ & $\begin{array}{c}\text { Escuelas Aguirre } \\
(01-05)\end{array}$ \\
\hline Escuelas Aguirre (01-05) & $-0,2$ & 0,2 & 1 \\
Escuelas Aguirre (08-12) & 0,2 & 1 & 0,2 \\
Escuela Aguirre (14-18) & 1 & 0,2 & $-0,2$ \\
\hline
\end{tabular}

Kendall Functional Correlation for $\mathbf{P M}_{10}$.

Table 4.

\begin{tabular}{|l|ccc|}
\hline Station (Years) & $\begin{array}{c}\text { Escuelas Aguirre } \\
(14-18)\end{array}$ & $\begin{array}{c}\text { Escuelas Aguirre } \\
(08-12)\end{array}$ & $\begin{array}{c}\text { Escuelas Aguirre } \\
(01-05)\end{array}$ \\
\hline Escuelas Aguirre(01-05) & 0,6 & $-0,6$ & 1 \\
Escuelas Aguirre (08-12) & $-0,2$ & 1 & $-0,6$ \\
Escuela Aguirre (14-18) & 1 & $-0,2$ & 0,6 \\
\hline
\end{tabular}

Kendall Functional Correlation for $\mathrm{NO}_{2}$.

Table 5.

\begin{tabular}{|l|ccc|}
\hline Station (Years) & $\begin{array}{c}\text { Plaza España } \\
(14-18)\end{array}$ & $\begin{array}{c}\text { Plaza España } \\
(08-12)\end{array}$ & $\begin{array}{c}\text { Plaza de España } \\
(01-05)\end{array}$ \\
\hline Plaza España (01-05) & 0 & 0,4 & 1 \\
Plaza España (08-12) & 0,2 & 1 & 0,4 \\
Plaza España (14-18) & 1 & 0,2 & 0 \\
\hline
\end{tabular}

Table 6. 
Kendall Functional Correlation for $\mathrm{NO}_{2}$.

\begin{tabular}{|l|ccc|}
\hline Station (Years) & $\begin{array}{c}\text { Barrio del Pilar } \\
(14-18)\end{array}$ & $\begin{array}{c}\text { Barrio del Pilar } \\
(08-12)\end{array}$ & $\begin{array}{c}\text { Barrio del Pilar } \\
(01-05)\end{array}$ \\
\hline Barrio del Pilar (01-05) & $-0,4$ & 0 & 1 \\
Barrio del Pilar (08-12) & 0,2 & 1 & 0 \\
Barrio del Pilar (14-18) & 1 & 0,2 & $-0,4$ \\
\hline
\end{tabular}

On the other hand, the Escuela Aguirre air monitoring station displays correlations of 0.2 and $0.2\left(\mathrm{NO}_{2}\right.$ and $\left.\mathrm{PM}_{10}\right)$ when it comes to the recession and recovery (2008-2012 and 2014-2018), which proves that pollution trends are practically unrelated. In other words, even if pollution levels had decreased during the crisis (see Figs. 3a and 3b), throughout the recovery phase they started to increase anew, although it is worth highlighting that this increase has been less intense than during the booming years preceding the crisis.
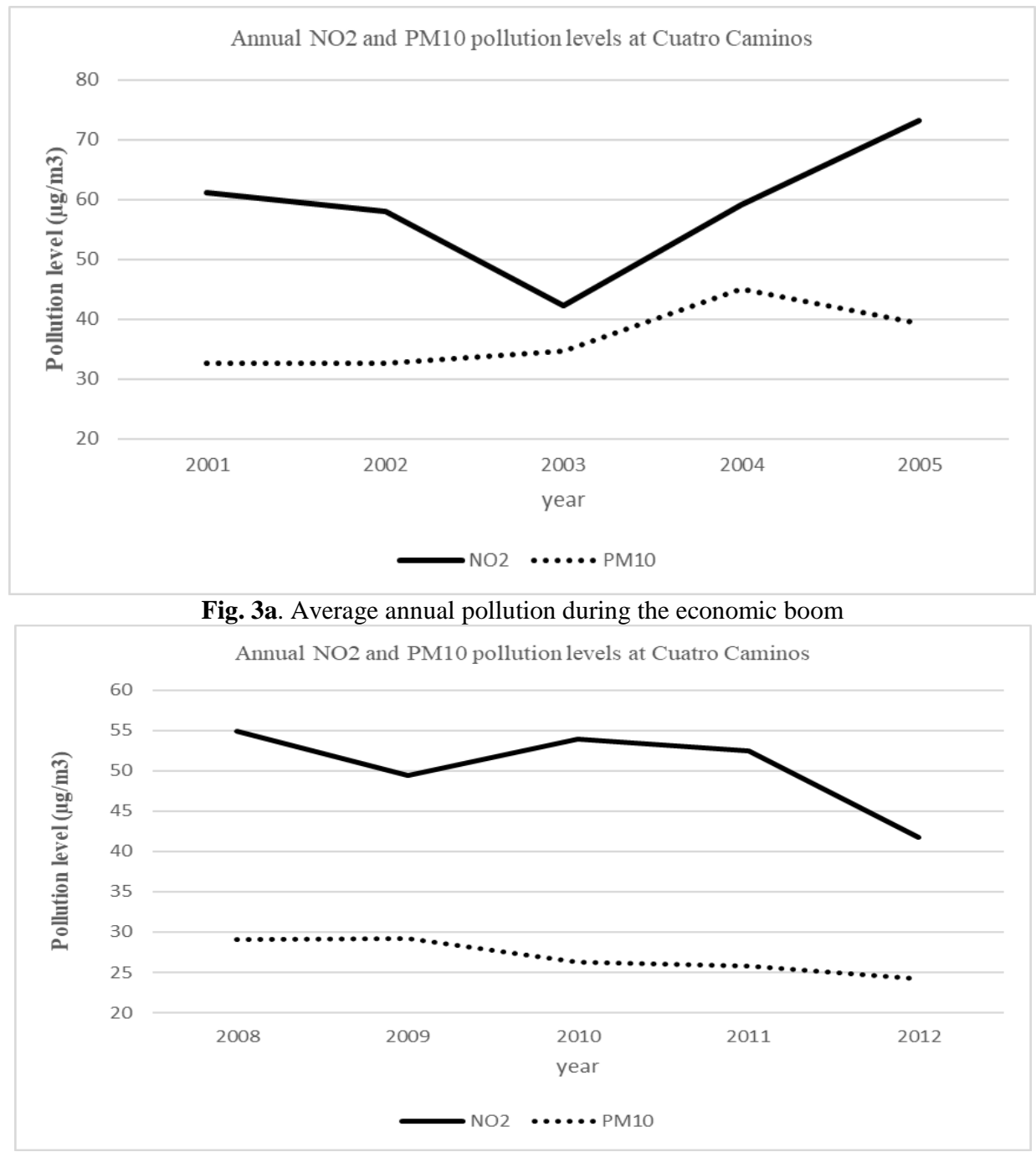

Fig. 3b. Average annual pollution during the recession.

(Source: authors' calculations based on data). 
From a statistical point of view, on Table 1 we can observe significant differences. As an example, Table 7 displays the significant differences that exist between average $\mathrm{PM}_{10}$ pollution levels during the analysed time frames at the Cuatro Caminos air monitoring station. This fact statistically confirms the differences regarding pollution levels for each phase of the business cycle. Hence, it is crucial to take into consideration the phase of the business cycle in the city under study when analysing environmental policy effectiveness, as these policies can be misinterpreted.

Table 7.

Mean differences between time frames.

\begin{tabular}{|l|c|c|c|}
\hline Monitoring Station & $\begin{array}{c}\text { Daily average ozone } \\
\left(\boldsymbol{\mu g} / \mathbf{m}^{3}\right)\end{array}$ & $\mathbf{N}$ & p-value \\
\hline Cuatro Caminos $\left(\mathrm{PM}_{10}\right) .(2001-2005)$ & 35.95 & 1584 & 0.00 \\
Cuatro Caminos $\left(\mathrm{PM}_{10}\right) .(2008-2012)$ & 27.27 & & \\
\hline Cuatro Caminos $\left(\mathrm{PM}_{10}\right) \cdot(2001-2005)$ & 35.95 & 1584 & 0.00 \\
Cuatro Caminos $\left(\mathrm{PM}_{10}\right) .(2014-2018)$ & 19.58 & & \\
\hline Cuatro Caminos $\left(\mathrm{PM}_{10}\right) .(2008-2012)$ & 27.27 & 1584 & 0.00 \\
Cuatro Caminos $\left(\mathrm{PM}_{10}\right) .(2014-2018)$ & 19.58 & & \\
\hline
\end{tabular}

\section{CONCLUSIONS}

After having used functional data in order to represent $\mathrm{PM}_{10}$ and $\mathrm{NO}_{2}$ pollution levels during the Spanish economy's boom, recession and recovery, and having selected the air monitoring stations located in Madrid City's areas suffering from heavy traffic, we could establish the similarities and differences in pollution levels for each phase of the business cycle. It is worth pointing out that this type of study involving environmental data framed within a functional context had never been done before.

The FKT coefficients calculated between different phases of the business cycle relative to those areas of Madrid that experience heavy traffic allow us to confirm that the inherent features to each phase of the business cycle act as automatic regulators of $\mathrm{PM}_{10}$ and $\mathrm{NO}_{2}$ pollution levels. In this sense it should be noted that during the booming years pollution levels regarding these substances were higher than during the crisis (negative correlations or close to zero correlations). The similarities found between the economic boom and the recovery prove the effect that economic activities, basically production and consumption, exert on pollution levels. This is due to the fact that the negative and close to zero correlations that we obtained regarding $\mathrm{PM}_{10}$ and $\mathrm{NO}_{2}$ levels between these two periods reflect that pollution levels differ significantly. Moreover, the follow-up of this study will allow to check what could happen to pollution levels depending on the current phase of the business cycle and will contribute to environmental policy decision-making in an urban context.

\section{R E F E R E N C E S}

ACDGMAS (2018). Dirección General de Medio Ambiente y Sostenibilidad - Área de Calidad Atmosférica (2019). "Informe anual sobre la calidad del aire de la Comunidad de Madrid. Año 2018" http://gestiona.madrid.org/azul_internet/ (viewed August $3^{\text {rd }}, 2019$ ).

Archer, C. L., Brodie, J. F., \& Rauscher, S. A. (2019). Global Warming Will Aggravate Ozone Pollution in the U.S. Mid-Atlantic. Journal of Applied Meteorology \& Climatology, 58(6), 1267-1278. https://doi.org/10.1175/JAMC-D-18-0263.1. 
Ceballos M. A., Segura P., Alarcón E., Gutiérrez E., Gracia J. C., Ramos P., Reaño M., García B., Villeta C., García M., Aranda J. A., Prima H., Veiras X., Bárcena J., García J., Belmonte P., Luengo P., Navascués E. \& Hernández K. (2018a) "La calidad del aire en el Estado español durante 2018”. Ecologistas en Acción, https://www.ecologistasenaccion.org/?p=96516.

EEA (2018). "Air quality in Europe - 2018 Report". European Environment Agency Reports, No 12/2018, ISSN 1977-8449. https://www.eea.europa.eu/publications/air-quality-in-europe-2018.

Fontana, M., Tavoni, M., \& Vantini, S. (2019). Functional Data Analysis of high-frequency load curves reveals drivers of residential electricity consumption. PLoS ONE, 14(6), 1-16. https://doi.org/10.1371/journal.pone.0218702.

Hysenaj, M. (2019). Dispersion model prospective of air pollution in Tirana. Geographia Technica, 14 (2), 10 19. doi: 10.21163/GT_2019.142.02.

Kendall, M. (1955). "A New Measure of Rank Corr elation". Biometrika.30 (1-2): 8189. https://doi.org/10.1093/biomet/30.1-2.81.

Kovács K.D. (2018). Evaluation of burned areas with Sentinel-2 using snap: the case of Kineta and Mati, Greece, july 2018. Geographia Technica, 14(2), 20-38. doi: 10.21163/gt_2019.142.03.

Lelieveld, J., Berresheim, H., Borrmann, S., Crutzen, P. J., Dentener, F. J., Fischer, H., Feichter, J., Flatau, P. J., Heland, J., Holzinger, R., Korrmann, R., Lawrence, M. G. , Levin, Z., Markowicz, K. M., Mihalopoulos, N., Minikin, A., Ramanathan, V., de Reus, M., Roelofs, G. J., Scheeren, H. A., Sciare, J., Schlager, H., Schultz, M. ., Siegmund, P., Steil, B., Stephanou E. G., Stier, P., Traub, M.,Warneke, C.,Williams, J., \& Ziereis, H. (2002). Global air pollution crossroads over the Mediterranean, Science 298, 794-799.

Li, R., \& Chow, M. (2005). Evaluation of reproducibility for paired functional data. Journal of Multivariate Analysis, 93(1), 81-101. https://doi.org/10.1016/j.jmva.2004.01.010.

López-Pintado, S., \& Romo, J. (2009). On the Concept of Depth for Functional Data. Journal of the American Statistical Association, 104(486), 718-734. https://doi.org/10.1198/jasa.2009.0108.

Medina-Ramón M., Zanobetti A., \& Schwartz J., (2006) “The Effect of Ozone and PM10 on Hospital Admissions for Pneumonia and Chronic Obstructive Pulmonary Disease: A National Multicity Study". American Journal of Epidemiology, 163 (6), pp 579-588, https://doi.org/10.1093/aje/kwj078.

Salvador, P., Artíñano, B., Viana, M. M., Alastuey, A., \& Querol, X. (2015). Multicriteria approach to interpret the variability of the levels of particulate matter and gaseous pollutants in the Madrid metropolitan area, during the 1999-2012 period. Atmospheric Environment, 109, 205-216. https://doi.org/10.1016/j.atmosenv.2015.03.008.

Spain Government, Ministry for Ecological Transition, 2018 (2018). "Evaluación de la calidad del aire en España - Ano 2018", https://www.miteco.gob.es/es/calidad-y evaluacion-ambiental/temas/atmosfera-y-calidaddel-aire/calidad-del aire/visor/default.aspx (viewed August $3^{\text {rd }}, 2019$ ).

Valencia, D., Lillo, R. E., \& Romo, J. (2019). "A Kendall correlation coefficient between functional data". Advances in Data Analysis and Classification. https://doi.org/10.1007/s11634-019-00360-z.

World Health Organization (2014). Burden of disease from ambient air pollution for 2012. Geneva, Public Health, Social and Environmental Determinants of Health Department, World Health Organization, Available from: http://www.who.int/phe/health_topics/outdoorair/databases/AAP_BoD_results_March2014.pdf?ua=1. 